\title{
Choice behavior of hippocampectomized rats in the radial arm maze
}

\author{
HIROSHIGE OKAICHI and YUKO OSHIMA \\ Doshisha University, Kyoto, Japan
}

\begin{abstract}
Rats with hippocampal lesions ( $n=16$ ), sham-operated controls $(n=5)$, and unoperated controls $(n=8)$ were trained on place and cue tasks in an elevated radial arm maze. Hippocampallesioned rats had impaired working memory and impaired cognitive-map formation. The behavior of the hippocampals in choosing arms was different from that of the controls even immediately after training began. The hippocampals were not able to rapidly perceive the spatial requirements of the task and did not show the inherent stereotyped behavior employed by controls. Nonetheless, the hippocampals showed that they could learn problem-solving behavior as training progresses.
\end{abstract}

The functional involvement of the hippocampus in processing spatial information has been extensively discussed. A focal point is the debate between the cognitivemap theory (O'Keefe \& Nadel, 1978) and the workingmemory theory (Olton, Becker, \& Handelmann, 1979). In several experiments, researchers have attempted to verify these two alternatives. Some supported the cognitivemap theory (Morris, Garrud, Rawlins, \& O'Keefe, 1982; Nadel \& MacDonald, 1980), some supported the workingmemory theory (Olton \& Feustle, 1981; Olton \& Papas, 1979), and others supported both theories (Jarrard, 1983; Jarrard, Okaichi, Steward, \& Goldschmidt, 1984). To better understand these seemingly contradictory results, we analyzed the strategies that rats employed when they performed place and cue tasks in an 8-arm radial maze.

In the usual 8-arm-maze task, in which all arms are baited, normal rats are able to perform the task successfully by employing either the response strategy (Dale \& Innis, 1986; Foreman, 1985; Olton \& Werz, 1978) or the place strategy (Maki, Brokofsky, \& Berg, 1979; Olton, Collison, \& Werz, 1977; Olton \& Samuelson, 1976). These strategies make it possible for the rats to visit every arm without reentering arms that have already been visited in a given trial.

To verify the cognitive-map theory, an experimental design that prevents the use of a response strategy is required. To achieve this purpose, we employed the procedure used by Jarrard (1983), in which the same 4 arms (cues) out of 8 arms (cues) are always baited. In this way, working memory can be dissociated from reference memory. With this procedure, the rats are able to use the place, cue, or response strategy. However, the response strategy is not the best strategy to use in performing either the place or the cue task. For this reason, we expected

Requests for reprints should be sent to Hiroshige Okaichi, Department of Psychology, Doshisha University, Kyoto 602, Japan. that the controls would use the best strategy as training progressed, even if they used the response strategy in the early stages of training. The cognitive-map theory predicts that hippocampal-lesioned rats would employ the cue strategy for the cue task, but would not be able to use the place strategy for the place task and would, therefore, use a response strategy instead. The working-memory theory predicts that the hippocampals would display working memory impairments on any task. However, if the rats employ appropriate turning responses on the basis of the response strategy, they can choose all arms and thus obtain rewards without using working memory. The confinement procedure, in which the animal is confined in the center hub for a short period after choosing each arm, has been used to eliminate the occurrence of specific response patterns in a successive arm-choice situation (Beatty \& Shavalia, 1980; Olton \& Werz, 1978). Since we regard any response patterns as the result of the employment of the response strategy, we did not restrict the rats' choice behavior in this experiment.

The purpose of the present experiment was to reexamine the effects of hippocampal lesions on reference and working memory and on the ability to learn place and cue tasks in a partially baited 8 -arm radial maze. At the same time, we attempted to characterize the performance of hippocampal-lesioned rats by examining the different strategies employed by the lesioned and nonlesioned animals.

\section{METHOD}

\section{Subjects}

The subjects were 29 experimentally naive male albino rats of the Wistar strain. The rats were randomly assigned to hippocampal $(n=16)$, operated control $(n=5)$, or unoperated control $(n=8)$ groups. Each rat weighed $300-320 \mathrm{~g}$ at the time of surgery. Throughout the experiment, animals were housed individually in standard wire-mesh cages with water available at all times. Animals were maintained on a 12:12-h light:dark cycle in a temperature- and humidity-controlled room. 


\section{Apparatus}

The 8-arm radial maze was made of gray vinyl plastic and was elevated $50.0 \mathrm{~cm}$ above the floor. The octagonal center platform was $36.5 \mathrm{~cm}$ in diameter, and each arm, which radiated from a side of the octagon, was $70.0 \mathrm{~cm}$ long and $9.0 \mathrm{~cm}$ wide. The arms were bordered by side walls $2.5 \mathrm{~cm}$ high. Each wall had a $23.5 \times 7.0 \mathrm{~cm}$ guard at its proximal end in order to prevent the rats from moving between arms without returning to the center platform. An $8.0 \times$ $5.0 \mathrm{~cm}$ Plexiglas sheet was placed at the distal end of each arm. A well, $1.5 \mathrm{~cm}$ in diameter and $0.5 \mathrm{~cm}$ in depth, was drilled at the center of the sheet through which a sucrose solution reward was delivered.

In the place task, the maze was located in a large well-lit room that had several obvious extramaze cues, including a table, chairs, shelves, a rat-carrier containing rats, and an experimenter. These cues always remained in the same position with respect to the maze. The same maze and room were used for the cue task. The arrangements differed, however, in that (1) eight removable inserts of different colors and textures, covering the entire surface of each arm, were moved in a random order from trial to trial, (2) the maze was surrounded by eight $96 \times 150 \mathrm{~cm}$ screens of thin white silk, stretched on frames, and (3) a 60-W light bulb and reflector, located $62 \mathrm{~cm}$ above the maze, provided the only illumination during training. The large difference in brightness levels within and outside the screens minimized the possibility that the rats could use extramaze cues. The experimenter could easily see the rats without being seen by them.

\section{Procedure}

At least 1 week after surgery, the rats were handled on 2 consecutive days for $10 \mathrm{~min}$ each. A food-deprivation schedule was begun on the first handling day. The amount of food was adjusted daily so that body weight was maintained at $85 \%$ of the ad-lib weight, with a 5-g gain permitted during each week of the experiment. After handling, a group of 3 or 4 animals were placed on the maze for a 15 -min period on 4 successive days. Conditions were arranged for the place and cue tasks on alternate days. A $23 \%$ sucrose solution was available in a small glass jar at the center of the platform. Rats were allowed to explore the maze and to drink the solution.

During training, each rat was given two daily trials on each task (i.e., place and cue) for 5 days a week. The order of trials for the place and cue tasks alternated from day to day. After 4 correct arms (or cues) were baited with a $23 \%$ sucrose solution, the rat was placed in the center of the platform for a trial. The animal remained on the maze until all 4 rewards had been consumed, until 16 choices had been made, or until 5 min had elapsed, whichever occurred first.

The order of arm choices and the total running time were recorded. An entry was recorded only when all four feet were in an arm. In the place task, the 4 correct arms were randomly chosen for each subject. For each rat, the location of the baited arms, with respect to extramaze cues, did not vary. In the cue task, the 4 correct cues were also randomly chosen for each subject. Each rat could receive rewards at the arms with four particular kinds of inserts, although the inserts were randomly moved to different arms from trial to trial. Training trials continued for 5 weeks.

\section{Surgery and Histology}

All operated rats were pretreated with $0.1 \mathrm{cc}$ atropine sulfate, i.p., and then anesthetized with $50 \mathrm{mg} / \mathrm{kg}$ of sodium pentobarbital, i.p. The hippocampal lesions were produced by a Radionics FRG-4. Four electrode sites were used (AP $=-2.1, \mathrm{ML}= \pm 1.0$ and $\pm 2.7, \mathrm{DV}=-3.8$ from bregma). The temperature at the tip of the electrode was maintained at $56^{\circ} \mathrm{C}$ for $60 \mathrm{sec}$. The tip of the electrode for the operated control rats was inserted at four sites (AP $=-2.1, \mathrm{ML}= \pm 1.0$ and $\pm 2.7, \mathrm{DV}=-2.8$ from bregma), but current was not delivered.
At the conclusion of behavioral testing, each rat was perfused intracardially with $10 \%$ formalin. The brains were removed, sectioned $22 \mu \mathrm{m}$ thick on a freezing microtome, and stained with luxol fast blue and cresyl violet.

\section{RESULTS}

\section{Histology}

Figure 1 shows photomicrographs of coronal sections from a representative hippocampectomized rat. In each hippocampal-lesioned animal, the dorsal hippocampus and fimbria-fornix were completely severed bilaterally, but the ventral hippocampus was left intact. In addition to damage to the overlying cingulate cortex and corpus callosum, some portions of dorsal thalamic nuclei, stria terminalis, stria medullaris, and lateral septum were also damaged. Despite the extrahippocampal damage, there was no evidence for any relationship between this damage and performance. Both the hippocampals and the operated controls had some damage to the part of the neocortex through which the electrode had been inserted.

\section{Behavior}

Preliminary analyses of all dependent variables indicated that the operated and unoperated control groups performed equivalently. Therefore, the two groups were combined to form a single control group.

Memory errors were divided into reference-memory errors (RME), working-memory errors (WME), and

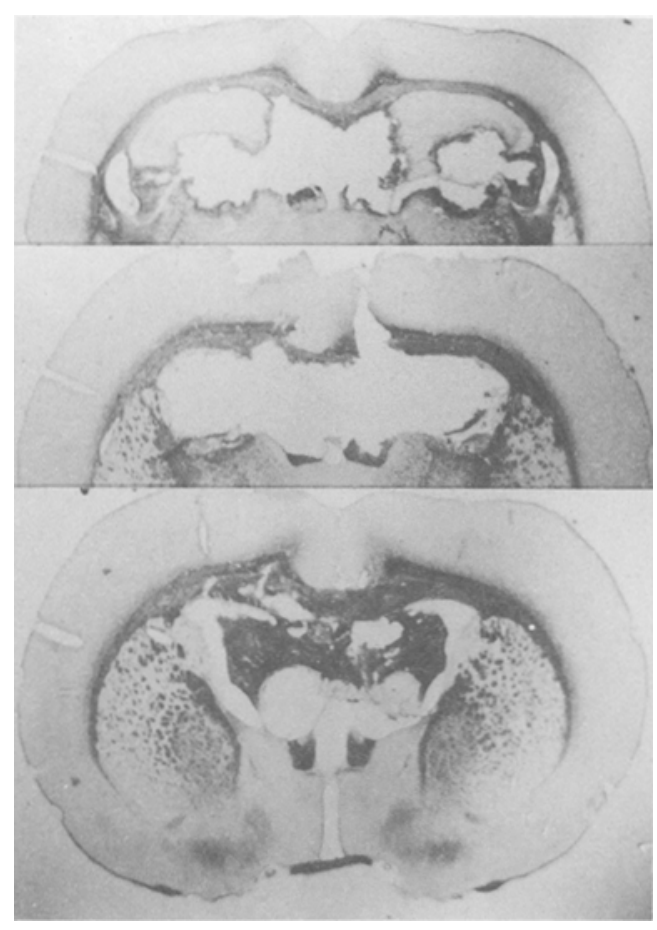

Figure 1. Photomicrographs showing coronal sections from a representative animal in the hippocampal lesion group. 
reference-working-memory errors (R-WME). RME involved initial entry into arms (or cues) that had always been unbaited. WME involved reentry into arms (or cues) that had previously been baited, but which had already been visited on that trial. R-WME involved reentry into unbaited arms (or cues) that had already been visited on that trial.

\section{Data Analysis}

Statistical analysis of the data was carried out using a factorial-design analysis of variance (ANOVA) with groups as a between-subjects factor and tasks and blocks as within-subject factors.

Data relating to these three types of errors are presented in Figure 2. Analysis of RME indicated that the secondorder interaction of groups $\times$ tasks $\times$ blocks was significant $[F(4,108)=13.78, p<.001]$, as were the main effects of groups, tasks, and blocks $[F(1,27)=36.54$, $F(1,27)=95.15$, and $F(4,108)=146.95$, respectively; ps $<.001$ for each]. Tests of simple main effects revealed that the controls on both tasks and the hippocampals on the cue task were able to significantly reduce RME as training progressed (all $p s<.001$ ), but that the hippocampals on the place task consistently made RME over all blocks.

As is evident from Figure 2, the controls made few WME on either task over all blocks of training. The hippocampals, by contrast, made WME on both tasks. ANOVA for WME indicated that the main effects of groups, tasks, and blocks were significant $[F(1,27)=$ $45.87, p<.001 ; F(1,27)=7.87, p<.01$; and $F(4,108)=16.48, p<.001]$, and that the first-order interactions of groups $\times$ tasks and groups $\times$ blocks were also significant $[F(1,27)=7.04, p<.05$, and $F(4,108)$ $=3.66, p<.01]$. Analyses of simple effects revealed that the hippocampals made significantly more WME than did the controls on the place and cue tasks $(p s<.001$ for both tasks) and that WME by the hippocampals were significantly reduced as training progressed $(p<.001)$.

The results of R-WME resembled those of WMEs on many points. The controls rarely made R-WME on both tasks. The hippocampals, in contrast, made many R-WME on the first block but reduced that number by training.

Turning responses were measured (1) during the first block of 10 training trials, in which both groups of animals had scarcely learned either task, and (2) over the course of the entire experiment, during which obvious performance differences between hippocampals and controls emerged. A turning response was defined in terms of the angle between successively chosen arms.

At first, the number of rats choosing arms at a constant angle $\left(45^{\circ}, 90^{\circ}, 135^{\circ}\right.$, or $\left.180^{\circ}\right)$ throughout an entire trial was counted during the first block of 10 training trials. A sequence in which all turning responses were $45^{\circ}\left(90^{\circ}\right.$, $135^{\circ}$, or $\left.180^{\circ}\right)$ was named a perfect sequence of $45^{\circ}\left(90^{\circ}\right.$, $135^{\circ}$, or $180^{\circ}$, respectively). Figure 3 shows the percentage of rats employing a perfect sequence in each trial. In the first trial, except for 3 control rats on the cue task, the rats show no perfect sequences. After the first trial, many more controls employed a perfect sequence than did the hippocampals. In the control group, all subjects employed a perfect sequence of $45^{\circ}$ whenever they used a perfect sequence on a trial. The rate for the controls rose to about $70 \%$ on the 4 th and 6 th trials. If the control rats that chose a turn other than $45^{\circ}$ only once in a trial (which could be termed a semiperfect sequence of $45^{\circ}$ ) were counted along with those that exhibited the perfect sequence of $45^{\circ}$, the rate reached $92.3 \%$ by the 6th trial on both place and cue tasks. After almost all of the controls had used the perfect sequence of $45^{\circ}$ on both tasks, the rate gradually decreased.

The data for the hippocampals looks much different. On no given trial did more than $25 \%$ of hippocampals employ a perfect sequence. When a perfect sequence was

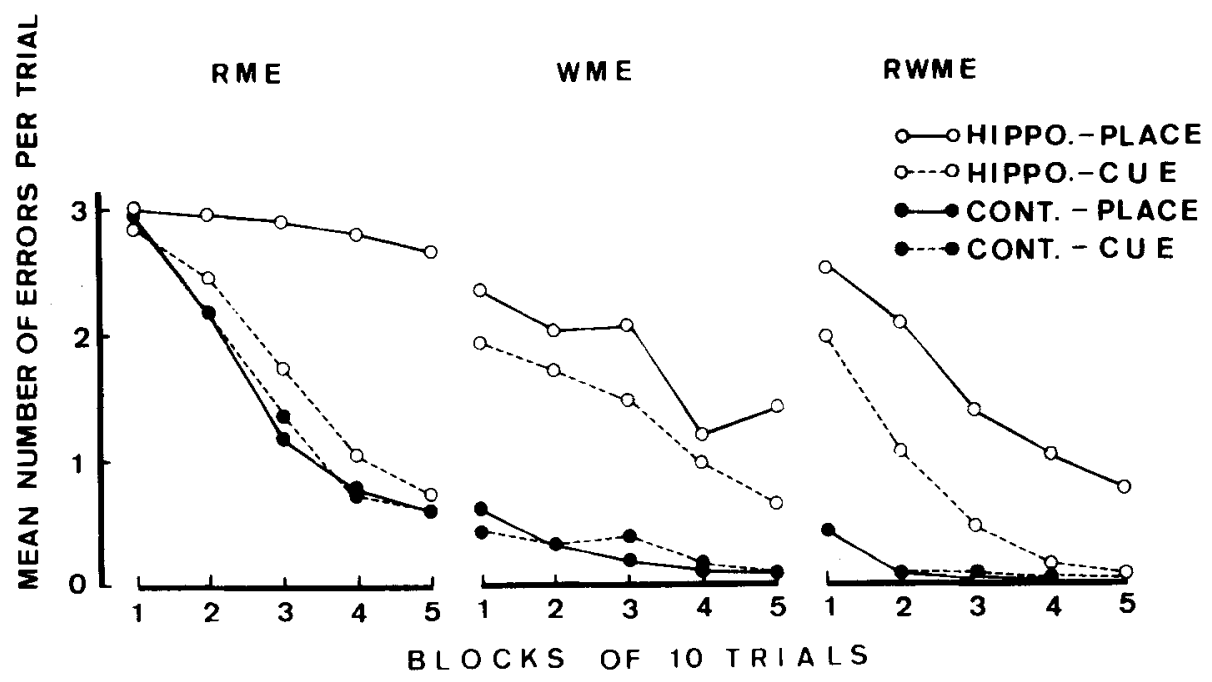

Figure 2. Mean number of RME, WME, and R-WME for hippocampals and controls on the place and cue tasks. 


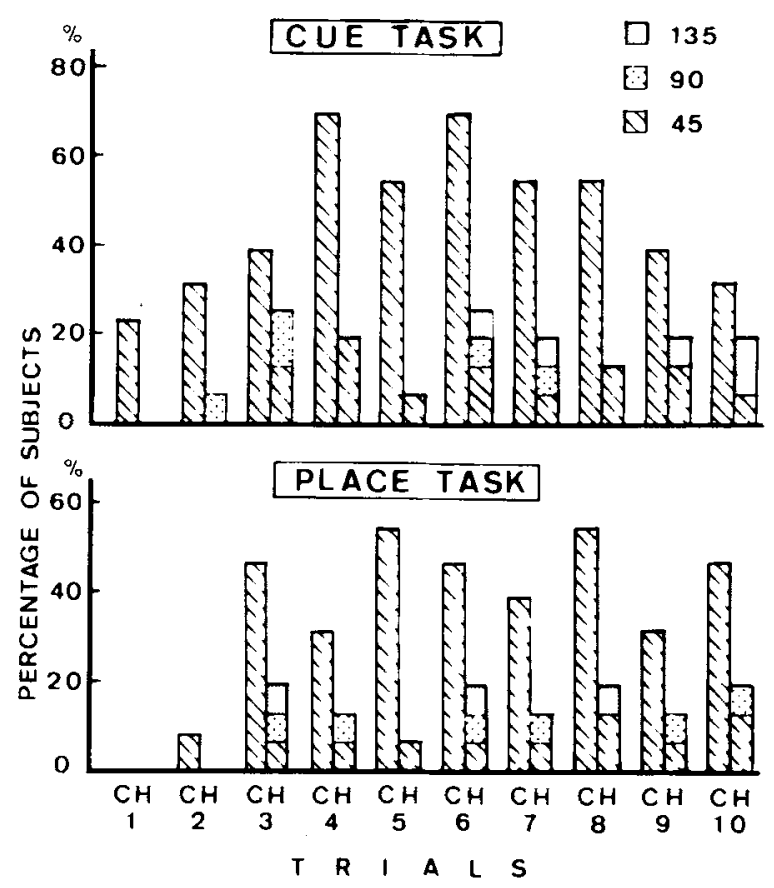

Figure 3. Percentage of rats employing perfect sequences of $45^{\circ}$, $90^{\circ}$, or $135^{\circ}$ at the first 10 trials of training ( $\mathrm{C}=$ controls; $\mathrm{H}=$ hippocampals). seen, it was not exclusively the perfect sequence of $45^{\circ}$, as with the controls, but was sometimes a perfect sequence of $90^{\circ}$ or $135^{\circ}$. Two hippocampals even employed a semiperfect sequence of $180^{\circ}$, only once choosing a turn other than $180^{\circ}$ within the trial. In these cases, one turning angle, though not used exclusively, often appears dominant. The dominant turning angles also changed from trial to trial.

As part of the second level of analysis, the four different turning responses $\left(45^{\circ}, 90^{\circ}, 135^{\circ}\right.$, and $\left.180^{\circ}\right)$ were counted in each block of 10 trials. Since animals in both groups rarely chose the same arm on two consecutive choices, the $0^{\circ}$ turning response was left out of the analysis. Although some animals showed a preference for either clockwise or counterclockwise turns, same-angle turning responses were combined without regard to direction, because turning-direction differences did not affect the results. Figure 4 shows the frequencies of the $45^{\circ}$, $90^{\circ}, 135^{\circ}$, and $180^{\circ}$ turning responses with the progression of training. The controls frequently employed the $45^{\circ}$ turning response in the first training block, but this rapidly diminished as training progressed. The $90^{\circ}$ and $135^{\circ}$ turning responses were much less preferred, and $180^{\circ}$ was chosen rarely. The frequency of these three turning responses remained at the same level from the beginning until the end of training. The hippocampals, in contrast, employed the $90^{\circ}$ and $135^{\circ}$ turning responses more often
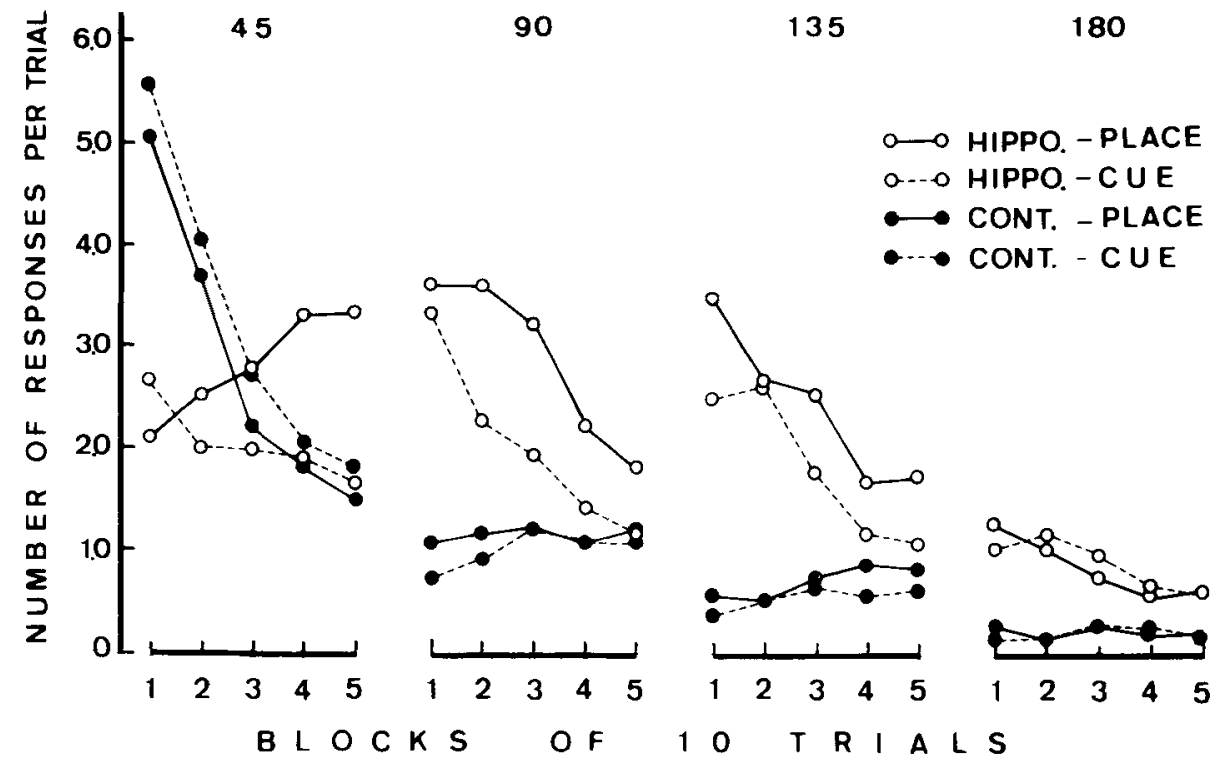

Figure 4. Mean number of $45^{\circ}, 90^{\circ}, 135^{\circ}$, and $180^{\circ}$ turning responses for hippocampals and controls on the place and cue tasks. 
than they did the $45^{\circ}$ turning response at the beginning of training. Also, they employed the $180^{\circ}$ turning response, although less frequently. The $90^{\circ}, 135^{\circ}$, and $180^{\circ}$ turning responses diminished with the progression of training. The $45^{\circ}$ turning response employed by the hippocampals for the place task increased, although the same turning response for the cue task showed a decline similar to that of the other turning responses. The ANOVA results for the $45^{\circ}$ turning responses revealed that a second-order interaction of groups $\times$ tasks $\times$ blocks $[F(4,108)=5.02, p<.001]$, as well as first-order interactions of groups $\times$ tasks, groups $\times$ blocks, and tasks $\times$ blocks $[F(1,27)=10.77, F(4,108)=24.83$, and $F(4,108)=8.48$; all ps $<.001]$, was significant. On $90^{\circ}, 135^{\circ}$, and $180^{\circ}$ turning responses, the first-order interaction of groups $\times$ blocks was significant $[F \mathrm{~s}(4,108)$ $=13.21,12.61$, and 3.40; $p<.001, p<.001$, and $p<.05$, respectively], but there was no significant second-order interaction.

\section{DISCUSSION}

We will discuss the cognitive-map and workingmemory theories mainly in terms of the analysis of reference-memory and working-memory errors. As the RME results shown in Figure 2 indicate, the hippocampals repeatedly entered arms that had not been baited during place-task training, but on the cue task they learned to enter arms that had never been baited. The results of R-WME, and especially WME, indicate impaired performance of the hippocampals in both the place and cue tasks. This effect was especially pronounced during the early stages of training. The characteristics of RME and WME found in this experiment are identical to those obtained in previous experiments (Jarrard, 1983; Jarrard et al., 1984).

Olton et al. (1979), who supported the working-memory theory, and Nadel and MacDonald (1980), who supported the cognitive-map theory, strongly assert that the workingmemory and the cognitive-map theories are mutually contradictory. Table 1 shows the anticipated performance of the hippocampal-lesioned rats, as predicted by each theory, and the summarized results of the present experiment.

From these results, we can conclude that the cognitivemap theory and the working-memory theory are not contradictory; each theory explains an aspect of hippocam- pal function, and each theory confirms that hippocampal lesions impair performance on tasks that require either cognitive mapping or working memory.

Now we would like to focus on the rats' turning responses. After only a few trials in the first block, the controls began to employ perfect or semiperfect sequences of $45^{\circ}$ turns and gradually abandoned this turning response as they began to learn the tasks. Seemingly, the controls were able to employ the $45^{\circ}$ turning response as the response strategy whether or not the arms were partially or fully baited. This systematic exploratory behavior is considered to be an innate behavior rather than an acquired one because it appears at a high rate after the rats have performed three to four trials. When all arms are baited, rats continue to use this strategy as the best strategy (Bolhouis, Bijlsma, \& Ansmink, 1986; Crusio, Schwegler, \& Lipp, 1987; Dale \& Innis, 1986). When the response strategy is not the best strategy, as in this experiment, rats shift to the most efficient strategy as training progresses.

The changes in the choice behavior of controls confirm previous suggestions that the response strategy is flexible in nature (Olton, 1979) and that rats can utilize the most effective strategy when more than one strategy is simultaneously available (Dale \& Innis, 1986). Our hippocampals, however, did not exhibit systematic exploratory behavior at the beginning of training. Rather than sticking to a single turning response, they shifted from one turning response to another, both within and across trials. They acquired the specific behaviors on the cue and place tasks predominantly by trial and error as training progressed (Figure 4). On the cue task, the hippocampals learned to differentiate baited arms from unbaited arms with the use of intramaze cues; they learned to successfully perform the cue task by using the cue strategy. On the place task, which hippocampals were not able to successfully acquire, they employed instead either the $45^{\circ}$ or $135^{\circ}$ turning response. This response strategy allowed the hippocampals to choose all arms without reentering the arms they had already visited so that they could obtain rewards more economically.

When the rats used the response strategy mentioned above, they could reduce working- but not referencememory errors. Figure 2 shows the decrease of WME and R-WME and the preservation of RME by the hippocampals on the place task with trial progression. The figure indicates the appropriateness of this explanation.

Table 1

Performance Tendencies of Hippocampectomized Rats as Predicted by the Cognitive-Map and Working-Memory Theories and the Results of the Present Experiment

\begin{tabular}{|c|c|c|c|c|c|c|}
\hline & \multicolumn{2}{|c|}{$\begin{array}{c}\text { Cognitive-Map } \\
\text { Theory }\end{array}$} & \multicolumn{2}{|c|}{$\begin{array}{c}\text { Working-Memory } \\
\text { Theory }\end{array}$} & \multicolumn{2}{|c|}{$\begin{array}{c}\text { Results of } \\
\text { Present Experiment }\end{array}$} \\
\hline & \multicolumn{2}{|c|}{ Task } & \multicolumn{2}{|c|}{ Task } & \multicolumn{2}{|c|}{ Task } \\
\hline & Place & Cue & Place & Cue & Place & Cue \\
\hline Working memory & 1 & $\rightarrow$ & $\downarrow$ & 1 & $!$ & 1 \\
\hline Reference memory & 1 & $\rightarrow$ & $\rightarrow$ & $\rightarrow$ & 1 & $\rightarrow$ \\
\hline
\end{tabular}

Note- $\downarrow=$ deficits in performance. $\rightarrow=$ no deficits in performance. 
This result supports our previous research in which we suggested that rather than behaving haphazardly, hippocampals employ the next-best strategy (Okaichi, 1987).

In summary, the hippocampus-lesioned rats have impaired working memory and cognitive-map formation. The behavior of the hippocampals in choosing the arms was different from that of the controls at the beginning of training: The hippocampals did not employ the response strategy that the controls employed. Nonetheless, the hippocampals showed that they could learn problem-solving behavior as training progressed.

\section{REFERENCES}

Beatty, W. W., Shavalia, D. A. (1980). Spatial memory in rats: Time course of working memory and effect of anesthetics. Behavioral \& Neural Biology, 28, 454-462.

Bolnouis, J. J., BiJlsma, S., \& Ansmink, P. (1986). Exponential decay of spatial memory of rats in a radial maze. Behavioral \& Neural Biology, 46, 115-122.

Crusio, W. E., Schwegler, H., Lipp, H. P. (1987). Radial-maze performance and structural variation of the hippocampus in mice: A correlation with mossy fiber distribution. Brain Research, 425, 182-185.

DALE, R. H. I., \& INNIS, N. K. (1986). Interactions between response stereotypy and memory strategies on the eight-arm radial maze. Behavioral Brain Research, 19, 17-25.

Foreman, N. (1985). Algorithmic responding on the radial maze in rats does not always imply absence of spatial encoding. Quarterly Journal of Experimental Psychology, 37, 333-358

JARRARD, L. E. (1983). Selective hippocampal lesions and behavior: Effects of kainic acid lesions on performance of place and cue tasks. Behavioral Neuroscience, 97, 873-889.

Jarrard, L. E., Oxaichi, H., Steward, O., Goldschmidt, R. B. (1984). On the role of the performance of place and cue tasks: Com- parisons with damage to hippocampus. Behavioral Neuroscience, 98 , 946-954.

Maki, W. S., Brokofsky, S., * Berg, B. (1979). Spatial memory in rats: Resistance to retroactive interference. Animal Learning \& Behavior, 7, 25-30.

Morris, R. G. M., Garrud, P., Rawlins, J. N. P., O'Keffe, J. (1982). Place navigation impaired in rats with hippocampal lesions. Nature, 297, 681-683.

NADEL, L., MacDonald, L. (1980). Hippocampus: Cognitive map or working memory? Behavioral \& Neural Biology, 29, 405-409.

OкAICHI, H. (1987). Performance and dominant strategies on place and cue tasks following hippocampal lesions in rats. Psychobiology, 15, 58-63.

O'KEEFE, J., NADEL, L. (1978). The hippocampus as a cognitive map. Oxford: Clarendon Press.

Olton, D. S. (1979). Maze, maps, and memory. American Psychologist, 34, 583-596.

Olton, D. S., Becker, J. T., \& Handelmann, G. E. (1979). Hippocampus, space, and memory. Behavioral \& Brain Science, 2, 313-365.

Olton, D. S., Collison, C., \& Werz, M. A. (1977). Spatial memory and radial arm maze performance of rats. Learning \& Motivation, 8, 289-314.

Olton, D. S., \& Feustle, W. A. (1981). Hippocampal function required for nonspatial working memory. Experimental Brain Research, 41, 380-389.

Olton, D. S., PAPAs, B. C. (1979). Spatial memory and hippocampal function. Neuropsychologia, 17, 669-682.

Olton, D. S., SAmuelson, R. J. (1976). Remembrance of places passed: Spatial memory in rats. Joumal of Experimental Psychology: Animal Behavior Processes, 2, 97-116.

Olton, D. S., WERz, M. A. (1978). Hippocampal function and behavior: Spatial discrimination and response inhibition. Physiology \& Behavior, 20, 597-605.

(Manuscript received April 11, 1990; revision accepted for publication July 24, 1990.) 